\title{
Effect of Teaching Program on Nurses' Performance Regarding Drugs that Affect Blood
} Coagulation in Coronary Care Unit

\author{
Rasha Galal Mohammed ${ }^{1}$, Olfat Abd El-Ghany Shawer ${ }^{2}$ \& Moggeda Mohamed Mehany ${ }^{3}$. \\ ${ }^{1 .}$ Nurse Specialist at General Assuit Hospital, Egypt. \\ 2. Assistant Prof of Critical Care and Emergency Department Faculty of Nursing, Assuit University, Egypt. \\ ${ }^{3 .}$ Assistant Prof of Critical Care and Emergency Department Faculty of Nursing, Assiut University, Egypt.
}

\begin{abstract}
Background Many patients admitted to coronary care unit(CCU) and receive several drugs, these drugs save their life at the other hand these drugs are considered threatened to their life so that nurses should ensure that is safe and effective through careful evaluation of the patient's response to therapy by direct observation of physiological measures Aim of this study: was to evaluate the effect of teaching program about drugs that affect blood coagulation on nurses' performance in CCU. Study design: Quasi experimental (pre- posttest) design was used. Setting: the study was conducted in CCU at Assuit General Hospital. Sample: (30) nurses from the previous mentioned setting. Tools; two tools: were utilized in the present study Tool (1) Knowledge assessment tool by using structure interview questionnaire for nurses was utilized, Tool (2) Assessment tool for nurses' practice by using observational check list for nurses' practice was utilized, Results: nurses' knowledge was improved significant from $25.8 \pm 6.48$ to $60.63 \pm 1.19$ and nurses practice was improved from $103.87 \pm 9.83$ to $169.9 \pm 1.86$ after implementation of teaching program about drugs that effect blood coagulation in CCU. Recommendation: continues nursing education and training program at $\mathrm{CCU}$ should be organized regarding drugs affecting blood coagulation.
\end{abstract}

\section{Keywords; Blood Coagulation, Nurses’ Performance \& Teaching Program.}

\section{Introduction}

Many patients admitted to coronary care unit and receive several drugs, these drugs save their life at the other side these drugs are considered threatened to their life so that nurses should ensure that is safe and effective through careful evaluation of the patient's response to therapy by direct observation of physiological measures, Reznek \& Azamy (2011). The drugs that are used to treat thromboembolic disorders fall into three major categories ; Anticoagulants (heparin, warfarin)are drugs that disrupt the coagulation cascade, and thereby suppress production of fibrin, Antiplatelets (aspirin) are drugs that inhibit platelet aggregation, and thrombolytic therapy (streptokinase)are drugs that promote lysis of fibrin and thereby cause dissolution of thrombi, Aschenbrenner \&Venable(2009).

Patient safety is a major concern for patients receiving drugs that affect coagulation because they're at risk for excessive bleeding. Take the following measures to protect patients from injury and minimize invasive procedures: Help consolidate required blood withdrawals so the patient has fewer chances to bleed. Clearly document in the chart that the patient is on this drug, to alert other caregivers that invasive procedures could lead to blood loss.se compression dressings over areas that could bleed, Tomaselli et al., (2017).

Patient characteristics can also increase bleeding. Studies show that the bleeding risk is increased with the following: Advanced age, diabetes, anemia, hypertension, CHF, female sex, history of stroke, renal failure, and liver disease

So these drugs must be used with extreme caution in all patients for whom there is a high risk likelihood of bleeding, Johnson et al., (2017).

The most common cause of medication errors is a lack of information related to medication therapy this can lead to complications through dose omission, extra dose, wrong dose/overdose, lab error in monitoring, medication is given at the wrong time, under dose, prescription refill delayed, wrong patient and drug-drug interaction so nurses need to know about all drugs a patient is taking, so that minimize adverse effects of these drugs through monitoring the patients closely for signs of blood loss, Barr \& Epps (2019).

Teaching programs for nursing staff constitutes an important part. These programs are urgently designed to assist staff nurses in developing and enhancing their skills needed to provide high standards of care to their patients, Mahmoud et al., (2016). It helps them to accept responsibility for their professional development. The educational program is designed to assist nurses to maintain and improve their competencies and to acquire new knowledge and practice, Woodward (2000). 


\section{Significance of the study}

Patients who are receive drugs that can affect blood coagulation need a special nursing care to improve patient out come and prevent complication. In (20162017) of Medical record of General Assuit Hospital about 960 Patients admitted to coronary care unit. The development of knowledge and skills is an essential component of professional development in nurse education programs, so that this study will improve nurses' knowledge to practice safely for such group of patients.

\section{Aim of the study}

The aim of this study is to evaluate the effect of teaching program about drugs that affect blood coagulation on nurses' performance in coronary care unit.

\section{Research Hypotheses}

1) There will be significance difference between post-test nurses' knowledge score to the pretest nurses' knowledge score following implementation of teaching program.

1) There will be significance difference between post-test nurses' practice score to the pretest nurses' practice score following implementation of teaching program.

2) A positive relation will exist between knowledge and practice score by nurses who will receive the teaching program.

\section{Subjects \& Method \\ Research design}

Quasi experimental (pre \& posttest) design was used to achieve the aim of the study

\section{Setting}

The study was conducted in the coronary care unit at Assuit General Hospital

\section{Sample}

All available staff nurses(30) who worked at the coronary care unit, the staff nurses include both sexes, with different age, different years of experience, different qualification (20 have Technical Institute of Nursing, 5 have faculty of Nursing, and 5 have Secondary Nursing)

\section{Tools of data collection}

\section{Tool (1): knowledge assessment tool}

This tool will be developed by the researcher based on related literature to assess nurses' knowledge related to drugs that affect blood coagulation in CCU. This tool consists of two parts

Part (1): Nurses demographic data such as age, sex, years of experience qualification, marital status and their attendance of related course training

Part (2): Structure interview questionnaire to assess nurses' knowledge this part include question to assess nurses' knowledge about drugs that affect blood coagulation such as what are the drugs that affect blood coagulation, mechanism of action of each category, side effect, indication, contra indication, complication, uses, and nursing care of this patient.

It was categorized into two levels, satisfactory if total score of knowledge $75 \%$ or more and unsatisfactory if total score of knowledge less than $75 \%$.

This knowledge covered by questions answered by nurses themselves

Tool (2): Practice assessment tool by using observational check list for nurses' practices (Pamela 2015)

This tool will be developed by the researcher based on related literature, Pamela 2015 to assess nurses' practice related to steps procedure of giving drugs that affect blood coagulation, it consists of (administering oral medications, administering subcutaneous injection, and administering an intermittent intravenous infusion of medication via a mini-infusion pump) this tool was used before and after implementation of teaching program to evaluate nursing practice regarding drugs effect on blood coagulation. It was categorized into two levels, satisfactory if total score of practice $75 \%$ or more and unsatisfactory if total score of practice less than $75 \%$.

\section{Method}

\section{Data will be collected in three phases 1-Preparatory phase}

Permission to conduct the study was obtained from the hospital responsible authorities after explaining the aim and nature of the study, The tool was developed by the researcher based on the relevant literature reviewing, Content validity of the developed tool was tested by 7 experts in the field of the study (4 critical care nursing staff and 3 critical medicine staff) and the necessary modification was done.

\section{A pilot study}

- A pilot study was carried out in order to assess the feasibility and applicability of the tools and the necessary modification was done $10 \%$ (5 nurses) were not included in the study

- Reliability was tested tools nurses' knowledge assessment questionnaire and observation checklist by using Cronbach's alpha, coefficient $\mathrm{r}=0.823$ and 0.724 respectively which is acceptable.

\section{Ethical consideration}

- The research protocol was approved from ethical committee in the faculty of nursing

- There is no risk for nurses during application of the research 
- The study was follow common ethical principles in clinical research

- Consent was obtained from nurses that were willing to participate in the study, after explaining the nature and the purpose of the study

- Nurses was assured that the data of this research will be used only for the purpose of research

- Confidentiality and anonymity was assured

- Nurses have the right to refuse to participate and or withdraw from the study without any rational at any time

\section{Implementation phase}

The process consumed of data collection and implementation of teaching program, The researcher introduced herself to all nurses and explained the purpose and importance of the study so the approval for participation was secured from each nurse, Questionnaire sheet; it was handed to all participant of nurses to fill it before implementing the teaching program to evaluate the theoretical knowledge, needs and collected by the researcher, The time for the completion of the questionnaire sheet was ranged from 1- 15 minute, The researcher was determine the teaching program content based on the result of the questionnaire, Theoretical content about drugs that affect blood coagulation was given to the nurses on the form of sessions for 30 minute according to their needs, Needed explanations enquiries in addition to booklet in Arabic language was given to each nurse, These teaching program content of the booklet was based on the pre assessment result, The program was conducted over 4 sessions 4 times per week to cover all information related to drugs that affect blood coagulation in CCU, Session was arranged to take place when nurses working during morning shift in an attempt to maximize attendance, The nurses was divided into small groups each group 3-7 nurses so that the program not interferes with nursing daily, The nurses was observed for their practice while they are working during their shift twice before and after implementing the teaching program.

Teaching methods and learning activities: Lecture, discussion, and demonstration by using audiovisual aids, power point presentation and booklet which in Arabic by the researcher based on reviewing literature and poster about skills included steps of administering oral medications, administering subcutaneous injection, and administering an intermittent intravenous infusion of medication via a mini-infusion pump.

\section{Evaluation phase}

The evaluation of the program was done by the researcher twice before and immediately after implementation of teaching program through structure interview questionnaire to assess nurses' bio socio demographic data, nurses' knowledge related to drugs that affect blood coagulation, and to assess nurses' practice related to steps procedure of giving drugs that affect blood coagulation by using observational check list for nurses' practices. This was done to evaluate the effect of the teaching program on gaining nurses' knowledge and practice toward drugs that affect blood coagulation in CCU.

\section{Statistical design}

An appropriate statistical methods and testes was used for analysis of data by using SPSS program, All data were collected, coded, tabulated, and subjected to statistical analysis is performed by statistical packages SPSS in general, also Microsoft Office Excel was used for data handling and graphical presentation. The data were tested for normality using the Anderson-Darling test and for homogeneity variances prior to further statistical analysis. Categorical variables were described by number and percent $(\mathrm{N}, \%)$, where continuous variables described by mean and standard deviation (Mean \pm SD). Chi-square test and fisher exact test used to compare between categorical variables where compare between continuous variables by t-test and ANOVA TEST. A two-tailed $\mathrm{p}<0.05$ was considered statistically significant. We are used person Correlation to Appear the Association between scores .All analyses were performed with the IBM SPSS 20.0 software. 
Results

Table (1): percentage distribution of Socio demographic characters for studied nurses $(n=30)$.

\begin{tabular}{|c|c|c|}
\hline Socio demographic data & $\operatorname{No}(n=30)$ & $\%$ \\
\hline \multicolumn{3}{|l|}{ Age } \\
\hline $20-<30$ years & 22 & 73.3 \\
\hline $30-<40$ years & 8 & 26.7 \\
\hline Mean \pm SD & \multicolumn{2}{|c|}{$28.44 \pm 5.54(20-39)$} \\
\hline \multicolumn{3}{|l|}{ Sex } \\
\hline Female & 23 & 76.7 \\
\hline Male & 7 & 23.3 \\
\hline \multicolumn{3}{|l|}{ Marital status } \\
\hline Single & 12 & 40.0 \\
\hline Married & 18 & 60.0 \\
\hline \multicolumn{3}{|l|}{ Qualification } \\
\hline faculty of Nursing & 5 & 16.7 \\
\hline Technical Institute of Nursing & 20 & 66.7 \\
\hline Secondary Nursing & 5 & 16.7 \\
\hline \multicolumn{3}{|l|}{ Years of Experience } \\
\hline$<5$ years & 22 & 73.3 \\
\hline $5-10$ years & 2 & 6.7 \\
\hline$>10$ years & 6 & 20.0 \\
\hline Mean \pm SD & \multicolumn{2}{|c|}{$6.03 \pm 5.08(2-19)$} \\
\hline Courses & & \\
\hline No & 30 & 100.0 \\
\hline
\end{tabular}

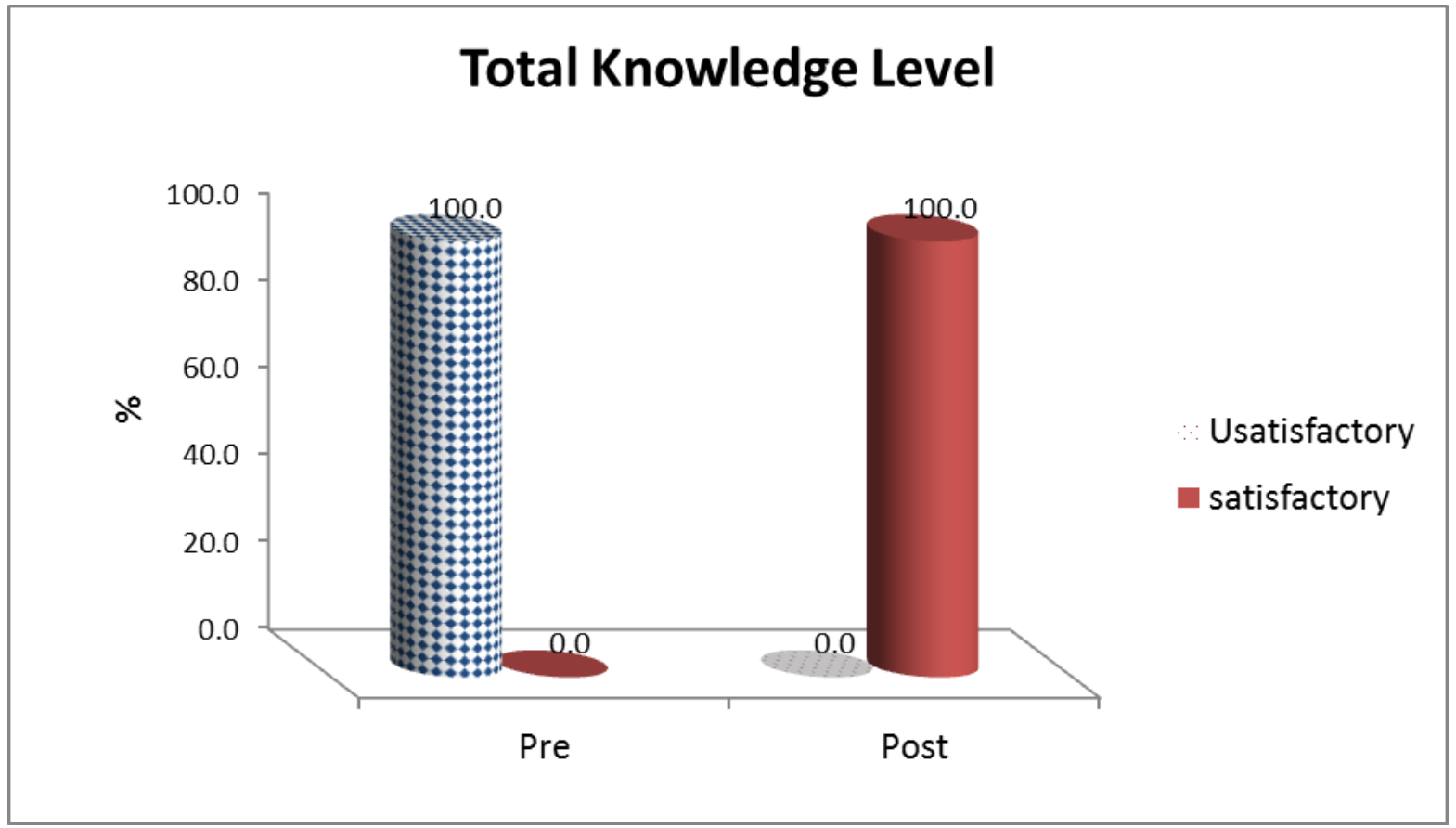

Figure (1): percentage distribution of studied nurses according to total knowledge level before and after implementation of teaching program. 


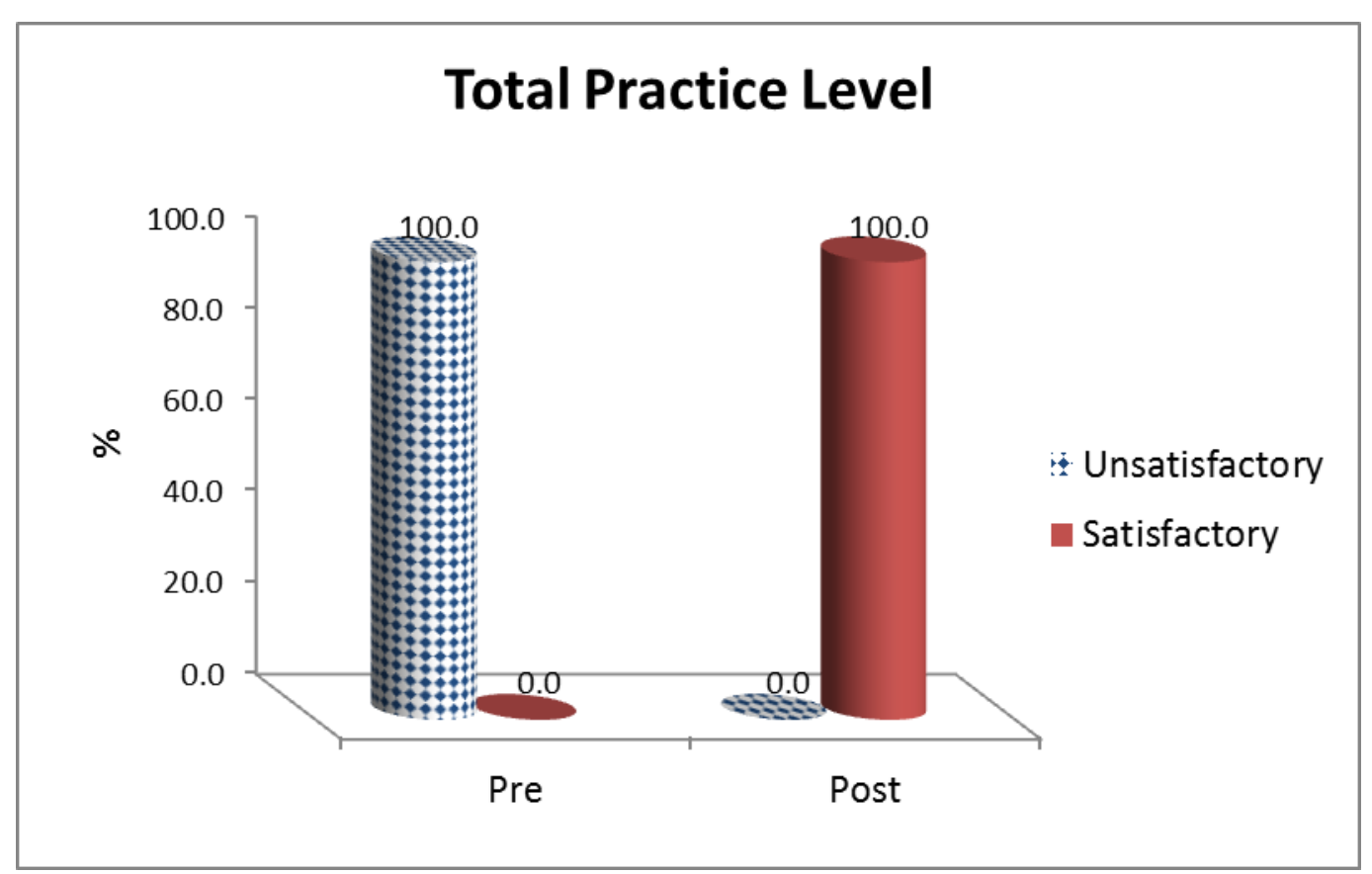

Figure (2): percentage distribution of studied nurses according to total Practices level before and after Implementation of teaching program.

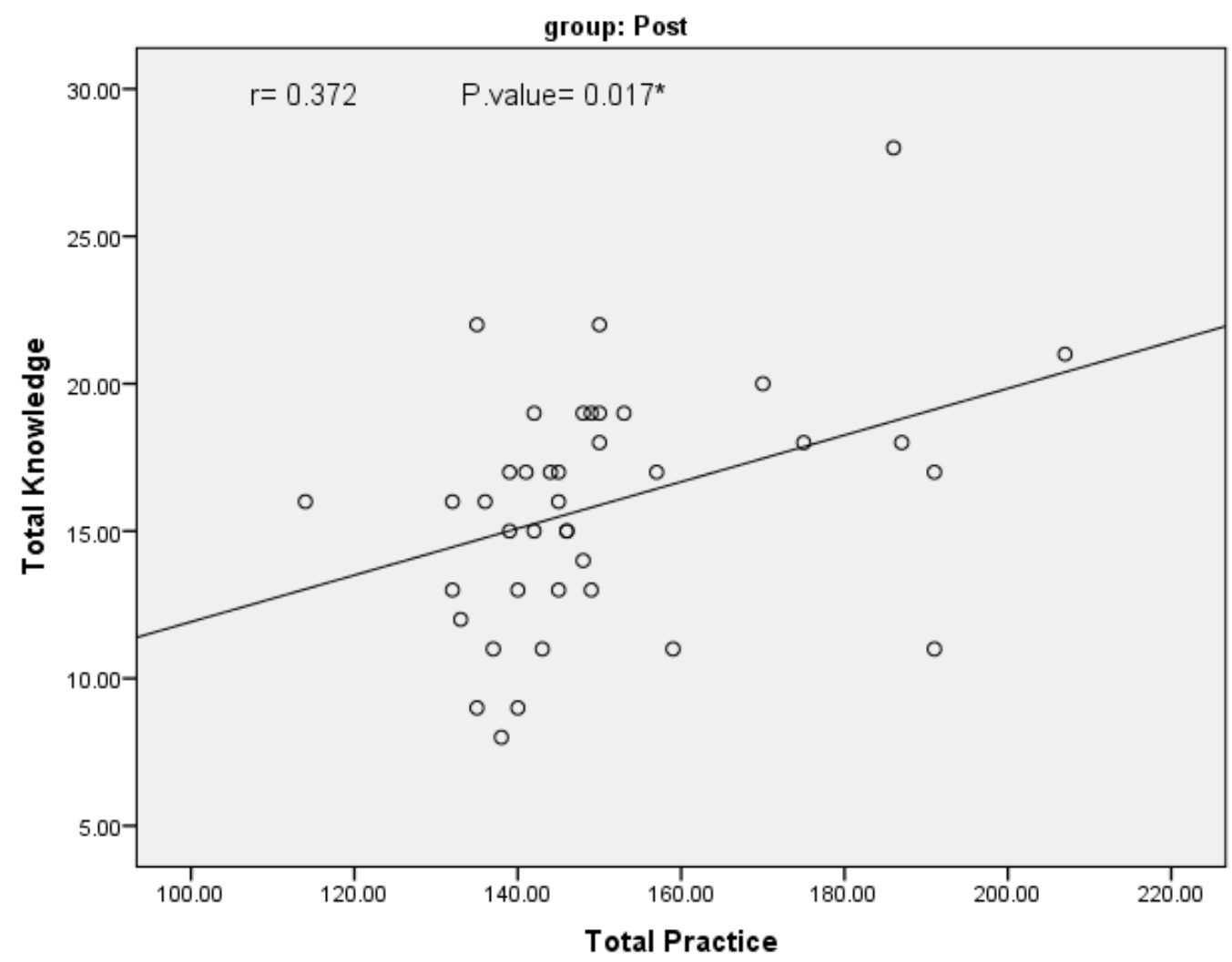

Figure (3): Correlation co-efficient between nurses' practice and their knowledge after implementation of teaching program. 
Table (2): Relationship between nurses' knowledge with their demographic data before and immediately after implementation of teaching program.

\begin{tabular}{|c|c|c|c|c|c|}
\hline & & Before teaching program & Immediately after teaching program & P1 & $\mathbf{P 2}$ \\
\hline & $\mathbf{N}$ & Mean \pm SD & Mean \pm SD & & \\
\hline \multicolumn{6}{|l|}{ Age group } \\
\hline $20-<30$ year & 22 & $24.45 \pm 6.01$ & $60.55 \pm 1.3$ & \multirow{2}{*}{0.058} & \multirow{2}{*}{0.511} \\
\hline $30-<40$ year & 8 & $29.5 \pm 6.68$ & $60.88 \pm 0.83$ & & \\
\hline \multicolumn{6}{|l|}{ Gender } \\
\hline Female & 23 & $25.83 \pm 6.46$ & $60.65 \pm 1.34$ & \multirow{2}{*}{0.969} & \multirow{2}{*}{0.878} \\
\hline Male & 7 & $25.71 \pm 7.06$ & $60.57 \pm 0.53$ & & \\
\hline \multicolumn{6}{|l|}{ Marital status } \\
\hline Single & 12 & $24.5 \pm 5.42$ & $60.92 \pm 1$ & \multirow{2}{*}{0.379} & \multirow{2}{*}{0.294} \\
\hline Married & 18 & $26.67 \pm 7.12$ & $60.44 \pm 1.29$ & & \\
\hline \multicolumn{6}{|l|}{ Education level } \\
\hline $\begin{array}{l}\text { Bachelor of } \\
\text { Nursing }\end{array}$ & 5 & $27 \pm 8$ & $61 \pm 1.22$ & \multirow{3}{*}{0.081} & \multirow{3}{*}{0.677} \\
\hline $\begin{array}{l}\text { Technical } \\
\text { Nursing Institute }\end{array}$ & 20 & $24.15 \pm 5.38$ & $60.5 \pm 1.28$ & & \\
\hline $\begin{array}{l}\text { Secondary } \\
\text { Nursing }\end{array}$ & 5 & $31.2 \pm 7.16$ & $60.8 \pm 0.84$ & & \\
\hline \multicolumn{6}{|l|}{ Experience years } \\
\hline$<5$ years & 22 & $24.32 \pm 6.07$ & $60.64 \pm 1.33$ & \multirow{3}{*}{0.067} & \multirow{3}{*}{0.706} \\
\hline $5-10$ years & 2 & $26 \pm 4.24$ & $60 \pm 0$ & & \\
\hline$>10$ years & 6 & $31.17 \pm 6.4$ & $60.83 \pm 0.75$ & & \\
\hline
\end{tabular}

Independent T- test

Table (3): Relationship between nurses' practice with their demographic data before and immediately after implementation of teaching program

\begin{tabular}{|c|c|c|c|c|c|}
\hline & \multirow[b]{2}{*}{$\mathbf{N}$} & \multirow{2}{*}{$\begin{array}{c}\text { Before teaching program } \\
\text { Mean } \pm \text { SD } \\
\end{array}$} & \multirow{2}{*}{$\begin{array}{c}\text { immediately after } \\
\text { teaching program } \\
\text { Mean } \pm \text { SD } \\
\end{array}$} & \multirow[t]{2}{*}{$\mathbf{P 1}$} & \multirow[t]{2}{*}{$\mathbf{P 2}$} \\
\hline & & & & & \\
\hline Age group & & & & \multirow{3}{*}{0.872} & \multirow{3}{*}{0.634} \\
\hline $20-<30$ year & 22 & $104.05 \pm 10$ & $170 \pm 1.38$ & & \\
\hline $30-<40$ year & 8 & $103.38 \pm 10$ & $169.63 \pm 2.92$ & & \\
\hline \multicolumn{6}{|l|}{ Gender } \\
\hline Male & 7 & $104 \pm 5.72$ & $169.71 \pm 2.43$ & \multirow{2}{*}{0.968} & \multirow{2}{*}{0.769} \\
\hline Female & 23 & $103.83 \pm 10.88$ & $169.96 \pm 1.72$ & & \\
\hline \multicolumn{6}{|l|}{ Marital status } \\
\hline Single & 12 & $104.83 \pm 10.89$ & $170.17 \pm 1.4$ & \multirow{2}{*}{0.668} & \multirow{2}{*}{0.532} \\
\hline Married & 18 & $103.22 \pm 9.32$ & $169.72 \pm 2.14$ & & \\
\hline \multicolumn{6}{|l|}{ Education level } \\
\hline Bachelor of Nursing & 5 & $113.4 \pm 10.16$ & $169.8 \pm 2.49$ & \multirow{3}{*}{0.051} & \multirow{3}{*}{0.817} \\
\hline $\begin{array}{l}\text { Technical Nursing } \\
\text { Institute }\end{array}$ & 20 & $102.25 \pm 8.95$ & $169.8 \pm 1.36$ & & \\
\hline Secondary Nursing & 5 & $100.8 \pm 8.84$ & $170.4 \pm 3.13$ & & \\
\hline \multicolumn{6}{|l|}{ Years of Experience } \\
\hline$<5$ years & 22 & $104.95 \pm 10.6$ & $169.73 \pm 1.55$ & \multirow{3}{*}{0.591} & \multirow{3}{*}{0.447} \\
\hline $5-10$ year & 2 & $99 \pm 2.83$ & $171.5 \pm 0.71$ & & \\
\hline$>10$ year & 6 & $101.5 \pm 8.09$ & $170 \pm 2.97$ & & \\
\hline
\end{tabular}

Independent T- test One way ANOVA 
Table (1): Shows Socio demographic data of studied nurses. It observed that the majority of studied nurses $(73.3 \%)$ were at the age group from 20 to 30 with Mean \pm SD $28.44 \pm 5.54(20-39)$. As regarding to sex the majority of studied nurses $(76.7 \%)$ were females. As regarding to marital status $(60 \%)$ of studied nurses were married. As regarding to qualification the majority of studied nurses $(66.7 \%)$ were technical degree. As regarding to years of experience the majority of studied nurses $(73.3 \%)$ had less than 5 years of experience with Mean \pm SD6.03 \pm $5.08(2-19)$. It observed that all of nurses (100\%) didn't receive any training program about drugs affecting blood coagulation.

Figure (1): Shows that $100 \%$ of studied nurses were unsatisfactory level of knowledge before implementation of teaching Program and $100 \%$ of studied nurses were satisfactory level of knowledge after implementation of teaching program.

Figure (2): Show that $100 \%$ of studied nurses were unsatisfactory level of practice before implementation of teaching program and $100 \%$ of studied nurses were satisfactory after implementation of teaching program.

Figure (3): Shows statistically significant correlation at $\mathrm{P}$. value $<0.01 *$.

Table (2): Show there was no significant relation between nurses' knowledge with their demographic data before and immediately after implementation of teaching program.

Table (3): Show there was no significant relation between nurses' practice with their demographic data before and immediately after implementation of teaching program.

\section{Discussion}

The aim of this study is to evaluate the effect of teaching program about drugs that affect blood coagulation on nurses' performance in coronary care unit.

As regarding to Socio demographic data:

The present studies observed that the majority of studied nurses were at the age group from 20 to 30 years old, females, technical nursing institute, and most of them had years of experience less than five years. This not in the same line with Ponikowski et al., (2016) who mentioned that; the administrators selected older age nurses to be able to perform mainly tasks in the intensive care unit effectively.

As well, Shorofi, \& Arbon, (2017) whom revealed that the majority of nurses working in ICU their ages ranged from 20-40 years, married, female, and have diploma of nursing, more than half of them their experience was more than 5 years.
This result in congruent with Eastwood et al., (2012) who reported that the majority of nurses who are working in ICU generally had bachelor degree in nursing, nurses' average age was 40 years. It may be due to the administrators selected older age nurses to be able to perform mainly tasks in the intensive care unit effectively. This result was in the same line with Considine et al., (2006) it means when the nurses' experience and qualification increase or if the nurses had training course on their favorable knowledge also improves.

As well, Chochinov et al., (2011) stated that nurses with less years of experience may require maximum additional instruction before they are ready to take a patient assignment; nurses working in one clinical specialty may need amount of instructions to acquire through training program.

In relation to attending any previous training program, it observed that all of nurses didn't receive any training program about drugs affecting blood coagulation. This might due to hospital haven't staff development training program. This result was supported by Schwartz et al., (2019) who said that nurses who are working in the intensive care unit needs additional education to provide optimal care for patients regarding blood coagulation drugs to prevent side effect.

Nurses' knowledge regarding drugs affecting blood coagulation:

The results of the exciting study detected that total score of nurses' knowledge about drugs affecting blood coagulation was poor before implementation of the teaching program, in my opinion this may be due to nurses didn't receive previous training program about drugs affecting blood coagulation and there isn't motivation from administration, no preemployment orientation program, insufficient number of nurses and lack of instructions. Also may be due to lack of updating information, and this might be due to the fact that basic education was not incorporated into either diploma or degree curricula. On the other hand, Egyptian nurses, particularly those works in bedside care are overworked because of the nursing shortage in the nursing staff. Therefore, they have limited time to enhance their knowledge about critical care.

More over all studied nurses were satisfactory level of knowledge after implementation of teaching program, in my opinion for significant improvement in nursing staff knowledge after application of teaching program about drugs affecting blood coagulation this improvement might be related to the fact that providing teaching materials as booklet and using group discussion for encourage with continuous 
feedback to ensure understanding and achievement of the specific objectives of the teaching program

This compatible with Oterhals et al., (2014) who found that; cardiac nurses need to improve their knowledge and practice patterns on oral anticoagulation therapy. This area of knowledge is important in order to deliver optimal care to cardiac patients and to minimize adverse effects of the treatment.

According to Kanki, (2019) reported that each organization and profession must set standards and objectives to guide individuals and practitioners in performing safe and effective care. Also not only must standards exist, but leader and managers also must see that subordinates know and understand the standards and employee must be aware that their performance will be measured in terms of their ability to meet the established standards.

In this respect, Nehls et al., (2016) mentioned that nurses must be able to expand their knowledge in this area through ongoing education, journal, and seminars. Consequently, teaching programs for nursing staff constitute an important part.

As well Skees, (2010) stated that; intended for professional nurses, continuing education is essential to safe and effective nursing care. The amount of knowledge required to take care of critically ill patients cannot be obtained simply through experience on the unit or at the bedside.

In this respect Zhao et al., (2016) indicated that to improve retention theoretical knowledge is needed and to achieve better outcomes frequent theoretical and practical training are needed and give a chance to repeat the difficult parts of the program.

Nurses' practice regarding drugs affecting blood coagulation:

The results of the exciting study detected that total score of nurses' practices about drugs affecting blood coagulation about all studied nurses was poor before implementation of the teaching program; more over all studied nurses were satisfactory level of practices after implementation of teaching program regarding administering a Subcutaneous, oral and intermittent intravenous therapy.

This in the same line with Fathimath et al., (2013) who mentioned that; regarding practices result of pretest indicates that the level of practices significantly increase with the level of education but effects of an educational program make the correlation not significant in posttest.

In the light of the study of Vargas et al., (2015) the nurses lack the efficiency of updating their practice after being and settled in the clinical environment for a longer time and possible explanation for this finding is that the workload.
In this respect Slater et al., (2018) who reported that teaching programs for nursing staff play an important role in assist in staff nurses in developing and enhancing their skills needed to provide high standards of care to their patients. This agreed with the present study as nurse's knowledge and practice improved after implementation of the nursing educational program.

This in the same line with Koo et al., (2016) their study revealed that an improvement in nurses' practice after the attendance at continuing nursing education sessions. Research findings indicated that continued nursing education programs increase knowledge, practice and can also improve attitudes.

In this respect Mahmoud et al., (2016) reported that teaching programs for nursing staff constitutes an important part. These programs are urgently designed to assist staff nurses in developing and enhancing their skills needed to provide high standards of care to their patients. This agreed with the present study as nurse's knowledge and practice improved after implementation of the nursing intervention protocol.

Regarding relationship between the total nurses' knowledge and their practice scores:

The current study demonstrated that there was a highly statistical significant difference in nurses' knowledge and practices after giving the educational program. In my opinion, the nurse should be having knowledge before practice. This study was in the line with Ozekcin et al., (2015) who expressed that the nursing care educational programs established to be effective in improving the knowledge and practice among staff nurses.

In this respect Bayoumi \& Mahmoud, (2017) such structured education will improve the knowledge and practice of staff nurses. Suitable intervention packages need to be developed and inservice education need to be given periodically for the effectiveness of qualitative nursing services.

This was not supported by Blanton et al., (2018) who mentioned that; knowledge and practice of health care providers were nearly not in the same level, Gijare, (2012) who reported opposite results regarding correlation between knowledge and practice, there was no correlation between knowledge and practice. As well Askarian, McLaws, \& Meylan, (2007) who found that there was no correlation between knowledge and practice.

Generally the present study concluded that; the nurses' knowledge and practice need an improvement so the study aim was achieved this in the same line with Phillips et al., (2019) who reported that; there is a need to improve cardiovascular nurses' knowledge and practices related to atrial fibrillation and anticoagulation therapy. 
Regarding relationship between the total nurses' knowledge scores and practices scores with their demographic characteristics:

The study result revealed that there was no statistical significant difference among nurses' knowledge and nurses' practices before and after the implementation of the teaching program and their socio-demographic. This mean that those characteristics cannot affected on the level of nurse's knowledge. These result may be due to the studied group were homogenous group, the majority of them nearly at the same age and the same years of experience. Nurses improve their practices by experience in the field of work, procedure of drug administration considered the main topic in curriculum of undergraduate nurses.

This result was not in agreement with Ayed et al., (2015) \& Meretoja et al., (2015) who found that the highest mean knowledge scores among younger nurses those who have the least experience.

This result not agreed with Fabrigar et al., (2006) that showed in his study that bachelor register nurse were significantly better patient outcomes.

In this respect Mohsen et al., (2016) reported that the level of performance of the nurses with baccalaureate degree is higher than the level of secondary school degree nurses.

Finally, the findings of the present study supported the implementation of teaching program about drugs affecting blood coagulation success in improvement nurses' knowledge and practices about drugs affecting blood coagulation

\section{Conclusion}

The following conclusion was drawn from the analysis of data; it was concluded that there were statistical significant improvement was founded for nurses' performance regarding drugs effect on blood coagulation in coronary care unit after implementation of teaching program.

\section{Recommendations}

Staff nurses should equipped by sufficient knowledge and practice regarding drugs that effect blood coagulation, and pre-employment orientation in services education and training program regarding drugs effect on blood coagulation.

\section{Limitation of the study}

For the findings presented in this paper some limitations should be taken into account. Small sample size represents a limitation that could affect generalization of results.

\section{References}

1. Aschenbrenner D., Venable S., (2009): Drugs Therapy In Nursing, $3^{\text {rd }}$ ed , Wolters- KluwerLippincott Williams Wilkins Lippincott, London , 543, 548

2. Askarian, M., McLaws, M., \& Meylan, M., (2007): Knowledge, attitude, and practices related to standard precautions of surgeons and physicians in universityaffiliated hospitals of Shiraz, Iran. International journal of infectious diseases, 11(3), 213-219.

3. Ayed, A., Sayej, S., Harazneh, L., Fashafsheh, I., \& Eqtait, F., (2015): The Nurses' Knowledge and Attitudes towards the Palliative Care. Journal of Education and Practice, 6(4), 91-99.

4. Pisani, I., Comellini, V., \& Nava, S., (2016): Noninvasive ventilation versus oxygen therapy for the treatment of acute respiratory failure. Expert review of respiratory medicine, 10(7), 813-821.

5. Barr, D., \& Epps, Q., (2019): Direct oral anticoagulants: a review of common medication errors. Journal of thrombosis and thrombolysis, 47(1), 146-154.

6. Blanton, J., Colwell, E., Walden, C., Davis, L., Hoang, C., Legred, J., \& Shwiff, S., (2018): Rabies exposures and pre-exposure vaccination practices among individuals with an increased risk of rabies exposure in the United States. Journal of the American Veterinary Medical Association, 252(12), 1491-1502.

7. Chochinov, H., Kristjanson, L., Breitbart, W., McClement, S., Hack, T., Hassard, T., \& Harlos, M., (2011): Effect of dignity therapy on distress and end-of-life experience in terminally ill patients: a randomised controlled trial. The lancet oncology, 12(8), 753-762.

8. Christel A., Woodward, (2000): Strategies for assisting health workers to modify and improve skills ;Developing quality health care - a process of change evidence and information for policy department of organization of health services delivery world healt organization Geneva , $25-26$

9. Considine, J., Botti, M., \& Thomas, S., (2006): The effects of specific educational preparation on emergency nurses' clinical decisions regarding supplemental oxygen administration. Nursing \& health sciences, 8(2), 73-80.

10. Eastwood, G., Reade, M., Peck, L., Baldwin, I., Considine, J., \& Bellomo, R., (2012): Critical care nurses' opinion and self-reported 
practice of oxygen therapy: a survey. Australian Critical Care, 25(1), 23-30.

11. Fabrigar, L., Petty, R., Smith, S., \& Crites, S., (2006): Understanding knowledge effects on attitude-behavior consistency: The role of relevance, complexity, and amount of knowledge. Journal of Personality and Social Psychology. 90(4): 556-577.

12. Fathimath S., Jancy G., Jancy T., (2013): Assessment of knowledge regarding critical ill among staff nurses working in selected hospital Mangalore with a view to develop an information pamphlet. International Journal of Recent Scientific Research. 2013;4(9):14101413

13. Gijare, M., (2012): Effectiveness of teaching on infection control practices among health care professionals. Sinhgad e Journal of Nursing, 2(2), 5-9.

14. Johnson, J., Caudle, K., Gong, L., Whirl-Carrillo, M., Stein, C., Scott, S., \& Anderson, J., (2017): Clinical Pharmacogenetics Implementation Consortium (CPIC) guideline for pharmacogenetics-guided warfarin dosing: 2017 update. Clinical Pharmacology \& Therapeutics, 102(3), 397-404.

15. Kanki, B., (2019): Communication and crew resource management. In Crew resource management (P.P. 103-137). Academic Press.

16. Koo, E., McNamara, S., Lansing, B., Olmsted, R., Rye, R., Fitzgerald, T., \& Team T., (2016): Making infection prevention education interactive can enhance knowledge and improve outcomes: Results from the Targeted Infection Prevention (TIP) Study. American journal of infection control, 44(11), 1241-1246.

17. Bayoumi, M., \& Mahmoud, N., (2017): Effect of education program on nurses' knowledge and practice regarding care of central venous line in pediatric hemodialysis: evidence-based practice guidelines. Egyptian Nursing Journal, 14(2), 87.

18. Mahmoud, A., Alseed, H., Abdallah, H., Awad, A., \& Elhussein, G., (2016): Assessment of knowledge and practice of nurses regarding oxygen therapy in elmak nimir university hospital., European Journal of Pharmaceutical and Medical Research ,3(4), 3035

19. Mohsen, M., Safaan, N., \& Okby, O., (2016): Nurses' Perceptions and Barriers for Adoption of Evidence Based Practice in Primary Care: Bridging the Gap. American Journal of Nursing Research, 4(2), 25-33.
20. Meretoja, R., Numminen, O., Isoaho, H., \& Leino-Kilpi, H., (2015): Nurse competence between three generational nurse cohorts: A cross-sectional study. International journal of nursing practice, 21(4), 350-358.

21. Nehls, N., Barber, G., \& Rice, E., (2016): Pathways to the $\mathrm{PhD}$ in nursing: an analysis of similarities and differences. Journal of Professional Nursing, 32(3), 163-172.

22. Oterhals, K., Deaton, C., De Geest, S., Jaarsma, T., Lenzen, M., Moons, P., \& Thompson, D., (2014): European cardiac nurses' current practice and knowledge on anticoagulation therapy. European Journal of Cardiovascular Nursing, 13(3), 261-269.

23. Ozekcin, L., Tuite, P., Willner, K., \& Hravnak, M., (2015): Simulation education: early identification of patient physiologic deterioration by acute care nurses. Clinical Nurse Specialist, 29(3), 166-173

24. Pamela Lynn, M., (2015): Wolters Kluwer; Skill Checklist for Taylor's Clinical Nursing Skills; A Nursing Process Aproach, $4^{\text {th }}$ ed Chap 5; 57:59, 72:74,87:89

25. Phillips, J., Heneka, N., Bhattarai, P., Fraser, C., \& Shaw, T., (2019): Effectiveness of the spaced education pedagogy for clinicians' continuing professional development: a systematic review. Medical education., 45

26. Ponikowski, P., Voors, A., Anker, S., Bueno, H., Cleland, J., Coats, A., \& Jessup, M., (2016): ESC Guidelines for the diagnosis and treatment of acute and chronic heart failure: The Task Force for the diagnosis and treatment of acute and chronic heart failure of the European Society of Cardiology (ESC). Developed with the special contribution of the Heart Failure Association (HFA) of the ESC. European journal of heart failure, 18(8), 891-975.

27. Reznek A., \& Azami R., (2011): Medication and patient care specific practice, areas, guidelines , American society of health system pharmacists , 68, $81 ; 95$

28. Schwartz, J., Schmader, K., Hanlon, J., Abernethy, D., Gray, S., Dunbar-Jacob, J., \& Peterson, J., (2019): Pharmacotherapy in older adults with cardiovascular disease: report from an American College of Cardiology, American Geriatrics Society, and National Institute on Aging workshop. Journal of the American Geriatrics Society, 67(2), 371-380

29. Shorofi, S., \& Arbon, P., (2017): Complementary and alternative medicine (CAM) among Australian hospital-based nurses: knowledge, attitude, personal and professional 
use, reasons for use, CAM referrals, and sociodemographic predictors of CAM users. Complementary therapies in clinical practice, 27, 37-45.

30. Skees J., (2010): Continuing education, a bridge to excellence in critical care nursing. Crit Care Nurs Q;33, 104-116.

31. Slater, P., Edwards, R., \& Badat, A., (2018): Evaluation of a staff well-being program in a pediatric oncology, hematology, and palliative care services group. Journal of healthcare leadership, 10, 67.

32. Tomaselli, G., Mahaffey, K., Cuker, A., Dobesh, P., Doherty, J., Eikelboom, J., \& Pollack, C., (2017): ACC expert consensus decision pathway on management of bleeding in patients on oral anticoagulants: a report of the American College of Cardiology Task Force on Expert Consensus Decision Pathways. Journal of the American College of Cardiology, 70(24), 3042-3067.

33. Vargas F., Saint-Leger M., Boyer A., (2015): Physiologic effects of high-flow nasal cannula oxygen in critical care subjects. Respir Care. 2015, 60(10):1369-76. doi:10.4187/respcare.03814

34. Zhao, J., Freeman, B., \& Li, M., (2016): Can mobile phone apps influence people's health behavior change? An evidence review. Journal of medical Internet research, 18(11), e287 